\title{
National Geographic: understand civil engineering differently
}

Mike Murray MSc, PhD, Cert Ed

Teaching Fellow, Department of Civil and Environmental Engineering, University of Strathclyde, Glasgow, UK
Stuart Ross MEng, CEng, MICE

Engineer, United Kingdom Middle East Africa Infrastructure, Arup, Glasgow, UK

\begin{abstract}
Undergraduate civil engineering students have access to a rich and diverse bank of textual and graphic knowledge concerning their chosen profession. However, over a number of decades, commentators have raised concerns that students have insufficient understanding of the role of civil engineering in society. Indeed, the call for universities to educate 'global engineers' emphasises the need for students to be schooled in the humanities, in parallel with their core computational studies. Unfortunately, engineering students in particular are not accustomed to regular exploratory reading. This paper considers the use of the National Geographic magazine as a means to ignite students' curiosity in the world around them. The results from a pilot study and a content analysis of a number of editions from over a decade show that this periodical regularly carries themes directly concerning the impact of civil engineering in society, be it political, financial, environmental, social or ecological.
\end{abstract}

\section{Introduction}

The title of this paper adopts an amended version of a wellknown strapline used by the Institution of Civil Engineers (ICE) as a call for young student engineers to widen their interest in global affairs. The paper examines the potential use of the National Geographic magazine $(\mathrm{NG})$ as a means to encourage exploratory reading and nurture a natural curiosity among undergraduate students. Indeed, Bourn and Neal (2008) call for higher education to prepare the 'global engineers' of the future. The correct wording of the strapline is

\section{When you understand civil engineering you see the world} differently. (ICE Scotland, 2013)

While referencing this call for a more global understanding, it is important also to recognise the role, and indeed responsibility, of civil engineers in modifying the planet's resources and influencing the behaviour of its inhabitants. Thomas Tredgold's (1788-1829) influential narrative within the ICE's 1828 Royal Charter - 'directing the great sources of power in nature for the use and convenience of man' - has attracted recent interest. Muir Wood (1978) reflected on the 'excesses of man's dominance over nature', while his son Muir Wood (2012) confirmed that the great sources of power in nature will continue to 'overwhelm man from time to time'. Moreover, perhaps the title of the ICE presidential address by Mustow (1993) - 'A world to serve' emphasises the change in outlook. Reflecting on Tredgold's definition offers undergraduate civil engineers a departure gate, not a revolving door, to reflect on their role in society. In particular, contemporary issues such as fracking and the exploration of the planet Mars should be on each student's radar, particularly given the name given to the roving vehicle exploring the planet - Curiosity. Indeed, curiosity fuels the narrative in this paper, and Millan (1996: p. 160) while having had the audacity to examine poetry in engineering education (but would have found favour with Thomas Telford; i.e. see Rolt, 2007: p. 74) conveys the intent of this research.

\footnotetext{
Whenever we pay real attention to the world, we engage in the process of discovery that frees our imaginations from our preconceptions and assumptions. This conflict between knowledge and imagination, between what we know and the unknown possibility, lies at the centre of engineering.
}

The primary aim of this paper is therefore to offer undergraduate students a 're-entry' point to their own studies, as captain of their own curiosity. It is argued that the $\mathrm{NG}$ provides an affordable, diverse and rich source of 'intuitive' knowledge that complements the traditional 'codified' knowledge in engineering textbooks and journals. Moreover, the acquisition of knowledge from social science publications can assist students to comprehend engineering 'in society' rather than assume a deterministic assumption that engineering is 'for society'. Furthermore, the plethora of subjects examined in the magazine reflects learning typically associated with that of a polymath engineer.

\section{A 'degree' of humanities?}

The history of the training and education of civil engineers has been a popular topic for researchers for over a century. Several 
Engineering Sustainability

Volume 167 Issue ES2
National Geographic:

understand civil engineering

differently

Murray and Ross
ICE presidents, particularly those holding professorial appointments (i.e. see Clarke, 2012) have chosen to present a longitudinal account of developments. Inglis (1941) noted his concerns for students developing a 'narrowness of vision' if they concentrated exclusively on scientific aspects of the profession. Hartley (1960: p. 12) wondered if over-specialised courses were damping down 'initiative and imagination and to limit a wider interest in the arts and humanities'. This was reiterated by Arms (1994), who revealed that first year civil engineers in the USA, who were exposed to a humanities curriculum, considered engineers in general to be 'creative problem solvers', while students who did not participate viewed engineers as 'number crunchers or gadget builders'. More recently, McCuen et al. (2011: p. 11) argued that

A study of the humanities improves self awareness, self confidence, and communications skill. A liberally educated civil engineer will be more socially sensitive to future developments and contribute a well-rounded perspective to the engineering profession.

Indeed, Bourn and Sharma (2008) refer to an employer's perspective calling for engineering graduates to have an 'understanding of how the world works, economically, politically, socially, culturally, technologically and environmentally'. Furthermore, Stoker (2012), an associate professor in civil and environmental engineering at the Massachusetts Institute of Technology, advises prospective students to secure good grades in maths and science while also showing an interest in ecology and the environment. Muir Wood (2012: p. 129) recommends that engineers need to 'think laterally, to speak out, and to study disciplines which are not traditionally seen as part of civil engineering, looking for innovative ideas which are capable of engineering application'. Moreover, the Joint Board of Moderators (JBM, 2009: p. 2013), who are responsible for overseeing the accreditation of civil engineering courses in the UK, call for teaching and learning processes that 'assist students to understand the interaction between engineering, the environment and society'. However, despite examples of best practice being evident (JBM, 2013) it appears that a wholesale adoption of a humanities curriculum within all civil engineering courses in the UK continues to be problematical.

\subsection{Curiosity and imagination}

It is likely that the majority of undergraduate civil engineers are dominant 'left brain' thinkers, with a preference for a logical, rational and a linear approach to problem solving employing mathematics. Indeed, these are the attributes through which pupils access civil engineering studies. Unfortunately, this can lead to students believing that civil engineers receive neatly packaged concise problems to resolve, and as Steels (2010) fears, graduates typically 'believe that analytical calculations will form the majority of their daily workload'. Indeed, former ICE presidents have spoken of the need for civil engineers: to possess 'not only intellect, but of character and heart' (Fox, 1899: p. 23); to understand when problems are best solved using 'common-sense rather than by mathematics' (Halcrow, 1946: p. 4); 'to be curious and excite debate' (Whitby, 2001: p. 6); and to have an 'ability to synthesise solutions, not simply an ability to analyse problems' (Jowitt, 2009: p. 2).

\subsection{A need for cultural emotional intelligence}

The calculated, objective and rational nature of an engineer's persona could be interpreted as lacking in empathy, or more likely, it is an underplayed emotion rather than a polar opposite. Indeed, engineers employed in international joint venture projects in the UK and overseas, and those connected 24/7 with colleagues in global offices will have experienced cultural dilemmas regarding language and etiquette. However, such cultural interpersonal communications could be considered functional and job specific, whereas a deeper understanding of indigenous cultures will hold value for the undergraduate civil engineer. For example, Wood (2003) examined the impact of a proposed commuter road through an indigenous first nations reserve to alleviate traffic congestion in Calgary, Canada; and Gryc and Da Silva (2013) provided a case study involving the design and construction of a kindergarten complex in Ghana and concluded that civil engineers need to 'move out of their technological comfort zone' and should be sensitive to the needs of local cultures so as to ensure infrastructure is socially sustainable.

Steels (2011: p. 93) appears to support the need to understand foreign cultures in his guide for early careerists - Initial Professional Development for Civil Engineers, and having spent a few days as a guest of Native Americans concluded that 'we had much to learn from them'. Former ICE president Jowitt (2009) also agrees.

As we enter what has also been called the Ecological Age, civil engineers need to adapt and learn from other disciplines and from other cultures that have a much closer relationship with the world in which we live - the American Indian, the Celt, the Inuit, the Aboriginal, the people of the Masai Mara, the Maori.

For undergraduate civil engineers to develop an emotional intelligence linked to an understanding and appreciation of national, regional and local cultures, it may require some students to ignite an otherwise unknown interest in anthropology. Perhaps these students find a natural affinity with organisations such as Engineers Without Borders (EWB UK, 2013). EWB's role in providing young people with an opportunity to utilise technology to assist tackling poverty around the globe has received support from Strathclyde University (UOS, 2013a), with students helping to establish the first Scottish branch in 2005. Indeed, Johnston et al. (2007) 
Engineering Sustainability

Volume 167 Issue ES2
National Geographic:

understand civil engineering

differently

Murray and Ross recommend exposing students to EWB early in their studies so that they learn to consider social and environmental issues when problem solving. Moreover, students who show an interest in EWB while at university are likely to develop an awareness of the Register of Engineers for Disaster Relief (see RedR UK, 2013) during their career. Indeed, as a founding patron of RedR, engineering consultant Arup (2012) has 'encouraged staff to train with the charity, provided financial support, and helped to shape its programmes, for over 25 years'.

Reference to a further charity, Bridges to Prosperity (B2P, 2013) highlights how a picture in the NG (see Morell, 2000) evoked an emotional yet practical response from an engineer. The picture featuring men in Ethiopia struggling across a damaged bridge inspired a construction company owner to found B2P. Perhaps proving that civil engineers are unique in knowledge and skills to act on global challenges.

\subsection{Global issues require a global perspective}

Bourn and Neal (2008) have examined the concept of the global engineer and point to the need for engineers to develop critical thinking skills including exploration of 'contentious and controversial aspects of engineering'. They raise concerns for engineering education.

Higher education needs to prepare engineers of the future with the skills and know how they will need to manage rapid change, uncertainty and complexity. Key here is the ability to tailor engineering solutions to the local social, economic, political, cultural and environmental context and to understand the impact of local action on the wider world. (Bourn and Neal, 2008: p. 2)

While fresher undergraduate students are exposed to news reports featuring natural and man-made disasters, anecdotal evidence suggests that the majority of students do not envisage themselves as providing solutions to such problems. Too many students appear to conceptualise their curriculum as 'bounded'; a narrowly defined commodity to be used solely in relation to fulfilling the requirements of summative assessments. Notwithstanding such problems, it can be seen that the concept of sustainable development, with regard to the Brundtland (1987) commission report, has provided a fertile source of topics to interest the undergraduate civil engineer. Indeed, while sustainable development is considered to be a relatively recent concept, the following list shows that for over 150 years, a series of ICE presidents have commented on associated themes (i.e. resource depletion; pollution; poverty).

McLean (1864: p. 157) spoke of the 'want of coal, arising from exhaustion'.

- Hawkshaw (1903: p. 11) examined the depletion of global timber resources and the difficulties of extracting tropical timber for use in civil engineering projects.
Manzoni (1961: p. 10) called for the planting of 'woodlands of oak for their sons and grandsons to harvest'.

- Harding (1964: p. 14) predicts that 'humanity might find itself being choked by its own waste products, atomic, industrial, and human'.

- Baxter (1977: p. 2) refers to the big problems facing society as 'food supply, material resources, energy and pollution'.

- Whitby (2001: p. 6) talks of 'urban decay, global climate destabilisation and poverty'.

The focus on global issues continues through the ICE Brunel International Lecture series.

Delivering sustainable development (Venables, 2001)

- Poverty alleviation - the role of the engineer (Singleton, 2003)

Water for the world - why is it so difficult? (Banyard, 2004)

Engineering civilisation from the shadows (Jowitt, 2006)

- Entering the ecological age - the engineer's role (Head, 2008)

- Shifting agendas: response to resilience. The role of the engineer in disaster risk reduction (Da Silva, 2013).

While the topics listed above would provide undergraduate students with a bank of knowledge related to global engineering problems, it may be that technical design and construction issues, associated with sustainable construction (i.e. embodied energy and carbon footprint) are more prevalent in the undergraduate course syllabi. However, one topic, professional ethics (i.e. see Armstrong et al., 1999; Fewings, 2009) appears to offer students a bridge linking what they may consider the bounded technical knowledge to that of global citizenship. Reading contemporary research such as Mustow (2006) 'Procurement of ethical construction products' offers an opportunity for students to reflect on the provision of materials and products from environmentally and socially responsible sources - topics that regularly receive an outing in the NG.

\section{Reading for a degree}

The genesis of this paper unravelled from the lead author's efforts to encourage more widespread reading of books, magazines and research publications among undergraduate students. The initiative features a book club with guest authors and a compulsory book reading exercise for new first year students (UOS, 2013b). The verbatim below, related to The Eden Project by Tim Smit (2011) indicates that, despite engineering students having an apparent stereotypical aversion to reading (Burstall, 1953; Marchant, 2002), they can be inspired by the outcome.

The Eden Project by Tim Smit is the most inspirational book I have read in a long time. The passion, enthusiasm and drive displayed by the team are something we can all learn from in every aspect of our 
Engineering Sustainability

Volume 167 Issue ES2
National Geographic:

understand civil engineering

differently

Murray and Ross lives... I can't wait to get the chance to go and visit Eden and see its wonders first hand. (First year student)

Although I found the book's main engineering and design processes enjoyable, I was initially hesitant that the book's content on plants and botany would not interest me at all. However, this was not an issue as I actually found these topics to be interesting and fascinating despite having limited knowledge on the subject. (First year student)

Additional coursework initiatives have required students to read six ICE presidential addresses (1820-2013) before preparing their own address (UOS, 2013c), reading New Civil Engineer as a means to learn about construction technology (UOS, 2013d) and as a fun festive art competition (Oliver, 2010) and frequent directed reading of The Structural Engineer, various ICE Proceedings and The Arup Journal (i.e. see Birch (2008) 'Waste as a driver of change' and Jackson (2011) 'The oceans as a driver of change').

The idea to promote the NG to students was driven by the lead author's academic interests in corporate social responsibility (Murray and Dainty, 2009), a personal interest in botany and biomimicry, and a general interest in global issues.

\subsection{The National Geographic Society}

The history of the National Geographic Society (NGS), its National Geographic magazine and its subsequent media interventions (television channel and website) are examined in a series of NGS publications (Bryan, 1987; Grosvenor, 1957; Jenkins, 2012). The first edition of the NG was published in 1888 with the inclusion of colour photographs by 1910 . While the magazine cannot be considered a technical resource for undergraduate students, it does offer commentary on the outputs of the work of civil engineers and frequently features verbatim from project stakeholders that would typically be consulted during an environmental impact analysis. Indeed, a cursory search of the NG indexes reveals coverage of mega civil engineering projects including the Panama Canal, with four articles from editions between 1904 and 1914 reprinted in Israel (1999) Building the Panama Canal; Morris's (1983) centenary celebration of the Brooklyn Bridge; and Newman's (1994) 'English Channel Tunnel'. While the undergraduate researcher seeking a scholarly examination of risk and optimism bias would need to consult alternative text (see Miller and Lessard, 2000; Priemus et al., 2008), the NG articles feature narrative and graphics exploring a 'humanistic' representation of engineering (i.e. see Grigsby, 2012) rather than place an emphasis on the objective rationality of a cost-benefit analysis.

While the purpose of this paper is not to document a history of civil engineering in the NG, of particular note are two special 13th issues published to date. Issues in February 1981 (Weaver et al., 1981) Energy - and in November 1993 (Graves, 1993) - Water - featured articles with content mirrored in the narrative of recent ICE presidential addresses. However, as argued in the title of this paper, undergraduate students should be encouraged to develop a wider curiosity about this planet. Regular reading of the NG could provide the stimulus for the student engineer to interpret the built and natural environment using an alternative lens. This would go some way to answering the call from Bell et al. (2011) for engineering to be considered as a sociotechnical profession and for engineers to assume the role of 'mediators between technology, nature, society and culture'.

Students who seek inspiration to engage with the NG would do no better than to consider the NGS's second president, Alexander Graham Bell (1847-1922), president from January 1898 until October 1903. In keeping with another inspirational engineer - Isambard Kingdom Brunel - Bell could be considered a polymath with a wide range of interests other than the telephone. Bryan (1987: p. 34) talks of his 'eccentric genius with a childlike enthusiasm for and fascination with the world around him'. Bell had several articles published in the NG and in 1903 his article on 'The tetrahedral principle in kite structure' ran to 32 pages. Given his interest in kites it may be that a recent $\mathrm{NG}$ article examining the use of drone aircraft (Horgan, 2013) would fascinate him more deeply than Grotzinger (2013). Should students see no relevance in this, then Muir Wood (2012: p. 127) offers assistance - 'civil engineering in space will challenge our inventiveness for lightweight, compact, collapsible, deployable structures', and that engineers should ' relish the excitement of searching for novel engineering solutions' to supporting human settlements in space. Bell would no doubt agree.

Self-education is a life-long affair. There cannot be mental atrophy in any person who continues to observe, to remember what he observes, and to seek answers for his unceasing hows and whys about things. (cited in Grosvenor and Morgan, 1997)

\subsection{A pilot study}

As a means to assess whether students would consider the NG a beneficial resource, a small survey of 101 students ( 29 first year and 72 third year) agreed to examine selected editions featuring reporting on issues such as flooding, population growth, infrastructure, energy supply and urban development. Before examining a minimum of two editions, the students were required to answer a Likert-type question - 'Do you think that the National Geographic can provide useful knowledge for undergraduate civil engineers?' After reading their selected magazines, the students were required to answer the same question again. Table 1 shows the impact of this pilot survey. The students were also required to give reasons for their response by writing a short sentence about each article read. The verbatim was categorised into themes and a sample of the returns is shown in Table 2. While it could be expected that the 


\begin{tabular}{lcrrrr} 
& No use & Neutral & Some use & Good use & Excellent use \\
\hline Before reading (third year) & & 13 & 13 & 41 & 5 \\
Before reading (first year) & & 7 & 5 & 13 & 4 \\
Totals & 2 & 20 & 18 & 54 & 9 \\
After reading two sample editions (third year) & 2 & 7 & 39 & 6 \\
After reading two sample editions (first year) & 2 & 2 & 11 & 70 & 3 \\
Totals & 2 & 9 & 9
\end{tabular}

Table 1. Student responses before and after reading copies of the National Geographic $(N=101)$

students would see value in articles concerning infrastructure, sustainability and so on, it was reassuring that one student, on reading a wildlife article, observed (possibly synthesised) the potential for a lightweight construction material through mimicking a toucan's beak. While the concept of biomimicry had not been discussed with the third year students, it has been introduced to first year students through the provision of Pawlyn (2011) Biomimcry in Architecture and Yiatros et al. (2007), whose ICE Proceedings paper examined biomimicry in structural design. Moreover, the Brunel lecture of Head (2008: p. 6) Entering the ecological age - the engineer's role, refers to 'using biomimicry principles as a framework to guide design and implementation and support the virtuous cycles of benefit'.

From the 101 students, 20 indicated that they had previously read the magazine at home or while attending an appointment with their dentist, general practitioner or hairdresser. Two
Infrastructure and cities

Energy

Sustainability and poverty

Disaster (design/recovery)

Materials and structures

Wildlife

Table 2. Sample of student responses after browsing two editions of the National Geographic (March 2006) (June 2006) common (April 2006) (July 2005) stand (April 2011) (November 2007) (December 2006)
It talked of the Indian superhighways and this could be of interest to civil engineers as it gives insight into the upcoming industry in India (October 2008)

Urban regeneration of old rail lines. Re-using old structures such as the Miracle above Manhattan can be useful in attracting new visitors (April 2011)

The high cost of cheap coal. Explains the process of mining coal and how mountains are moved

Nanotechnology. Explains the use of nanotechnology in solar panels, fire-resistant glass etc.

Struggle for the soul of Pakistan. The article about Pakistan could be useful when it speaks about the poor neighbourhoods (September 2007)

Global fish crisis - about overcrowded seas and how civil engineers could come up with a new strategy to overcome the problem (April 2007)

The Hayward Fault explains the way buildings are designed in areas where earthquakes are

Deepwater horizon - outlines the management issues, as well as cost-driven policy, which leads to the failure of the delivery pipe/cap. Impact of oil spill a concern to engineers in the oil sector

Inca building techniques. Building with precision stone could prove to be more environmentally friendly. It had proved its strength after five and half centuries of earthquakes, the buildings still

The acid threat examines corrosion of materials and this is a real issue for civil engineering

Not really, it was mostly about elephants (March 2007)

Wildlife section on toucan's beak - possible to mimic for lightweight constructional material 
Engineering Sustainability

Volume 167 Issue ES2
National Geographic:

understand civil engineering

differently

Murray and Ross students confirmed that they had a current subscription, with a third student being a former subscriber. The results in Table 1 indicate that on reviewing the sample magazines, a total of 11 $(11 \%)$ students considered the publication of some use towards their studies; $70(69 \%)$ students considered the magazine to offer good use, while nine ( $9 \%$ ) regarded it to be of excellent use in assisting their learning. One subscriber contrasted the
NG with other engineering publications and emphasised that it offered alternative but useful learning (Figure 1).

I think the most important feature of the magazine, which differs from hardcore engineering magazines like New Civil Engineer or The Structural Engineer, is that it focuses [sic] on the social side of things. Recalling from a recent issue on the Three-Gorges Dam, the

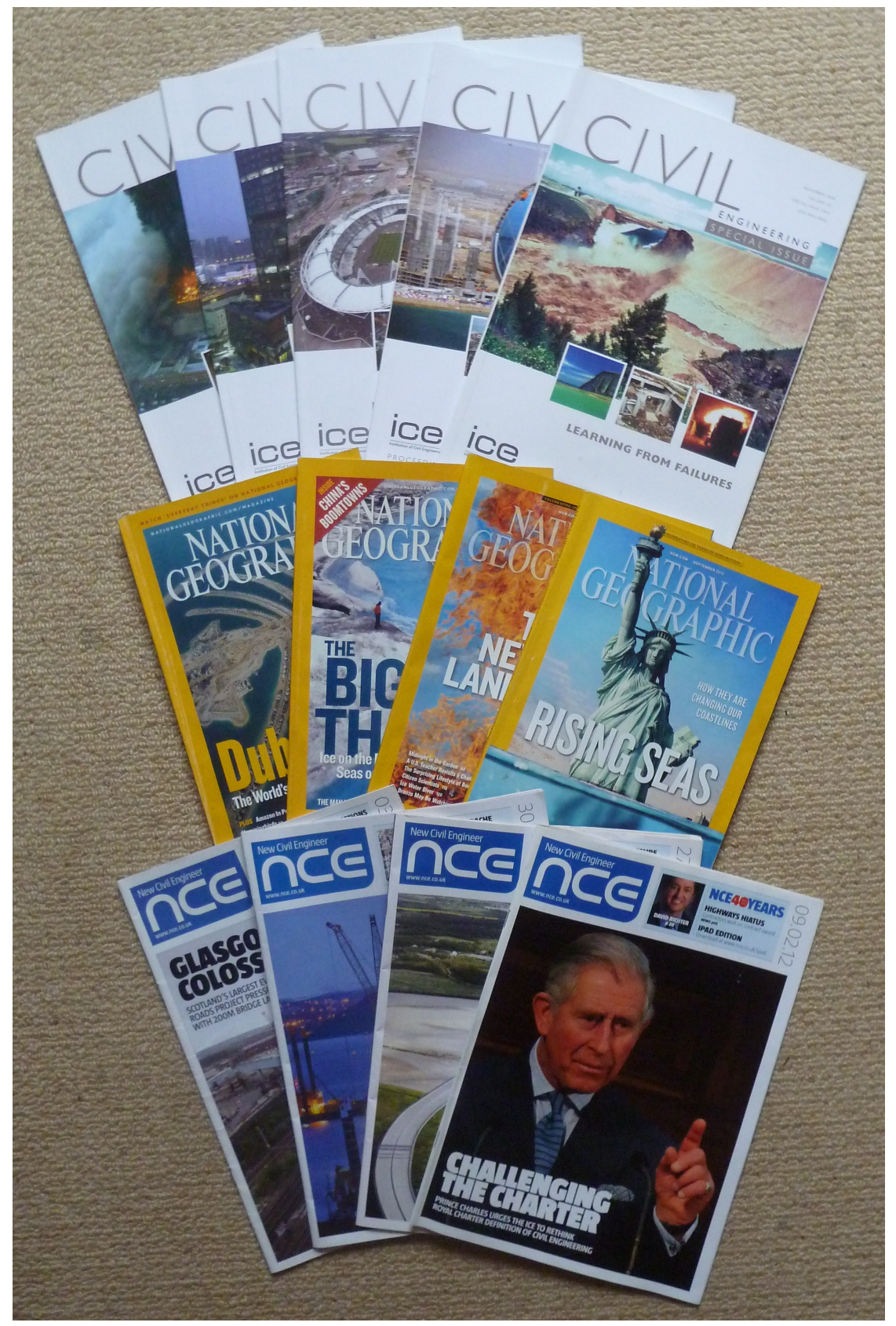

Figure 1. Magazine collage 
Engineering Sustainability

Volume 167 Issue ES2
National Geographic:

understand civil engineering

differently

Murray and Ross journalist wrote a very decent article on how the dam has shaped the way of life of the locals forever. (Third-year student)

The student who had cancelled his subscription explained that he was unable to devote sufficient time to read each issue. However, completing the questionnaire had renewed his interest in the magazine and he considered the publication to offer new knowledge contributing to his continued professional development.

I stopped it due to not getting through them each month, so I have a huge backlog to read now. I found that they covered a great range of articles, and do remember it covering articles related to Civil

Engineering, especially the boom in construction in Dubai. Perhaps now that I am on this course, if I went back then I would find more relevant content. (Third-year student)

Unfortunately, there appears to be a growing pattern of students 'satisficing' (at the expense of holistic understanding) through narrow 'rote' learning and 'cramming' knowledge before undertaking formal examinations. Regular reading of the NG would appear to offer students an opportunity to reevaluate how they conceptualise engineering knowledge, and its associated topics, above that of contributing solely towards a graduation parchment. Indeed, informal discussions with civil engineering students who were not part of the survey revealed two more subscribers to the magazine. The responses from both students provide additional corroborating evidence supporting the survey results.

I've had a subscription to National Geographic since I was about 15 . While many times it would appear to have nothing relevant, it sometimes has some very relevant pieces, and also gives context to how we work. I think it is best at describing the way humans relate to their surroundings. (Fourth year student)

I have had a subscription for quite a few years and would say that it was fairly useful for civil engineers. It is probably more focused on the human impact of construction rather than with the exact details of how things were built. I do think it is very useful for anyone studying environmental engineering as almost every article has a depiction of local ecosystems and wildlife, and why each is doing well/not so well. It gives you an idea of the kind of things we should assess before undergoing any project, which I find interesting. (Second-year student)

\section{Use of the NG as research data}

The previous section has demonstrated that the majority of students in the sample considered the NG to be of good use towards their studies. Clearly, the sample size does not permit the authors to make firm generalisations regarding the UK's population of undergraduate civil engineers. However, the results do suggest that the students who participated in the research may well consider this magazine of use when undertaking research for their own courseworks, design projects and dissertations. Indeed, the NG has been popular in providing knowledge that has been cited in engineering publications.

A cursory search within Google Scholar uncovered citations of the NG within the American Society of Civil Engineers publications. Hurricane Ike Field Investigations (ASCE, 2013) cited the article by McGee (1900) examining the aftermath of a hurricane in Galveston, USA. Wright and Zegarra (2000) Machu Picchu: A Civil Engineering Marvel cited the article by Henry Bingham (1913) on the discovery of the lost Inca estate. The paper by Litman (2006) in the Journal of Transport Engineering examined hurricanes Katrina and Rita, and cited the article by Bourne (2004) featuring flooding in New Orleans. A further article (Wilcox, 2012) in the ASCE's magazine Civil Engineering featured a charity, Bridges to Prosperity, and noted how the organisation's founder was influenced by a photograph in the NG article by Morell (2000) previously cited in this paper. Therefore, there are precedents for the NG being used in civil engineering publications, and this would suggest that it has sufficient useful content to be of value to the curious undergraduate civil engineer. It is therefore important not only to consider the perceived value by students based on a small number of sample editions, but to also carry out a wider content review to ascertain the scope of potential subjects that could be of interest.

\subsection{An indicative content analysis of the NG 2000-2013}

Table 3 shows the results of an indicative content analysis derived from searching the National Geographic Publications Index (2013) using ten keyword themes. The scope of the search was limited to articles published in the NG between January 2000 (volume 197, no. 2) to July 2013 (volume 224, no. 3). Results from other NGS publications (i.e. children's magazine, Traveller) were excluded. The choice of the keyword themes emerged from browsing selected hard copy articles of the NG. While this was a pleasurable activity and did uncover a rich resource for further reflection, the number of themes detected with relevance to civil engineering became cumbersome, ending in data saturation. Moreover, this practice tends to reflect a 'thematic analysis', whereas the purpose of this paper is to demonstrate that the NG has featured a sufficient number of relevant articles that would be of interest to undergraduate civil engineering students.

Table 3 shows the ten themes with the number of 'hits' shown in brackets. However, the subthemes provide a more extensive landscape justifying serious exploration by undergraduate students. Thus, it can be seen that from 25 articles featuring 'energy sources', 16 of these contained narrative related to 'environmental concerns'. Of course, real exploration and the 
Engineering Sustainability

Volume 167 Issue ES2
National Geographic:

understand civil engineering

differently

Murray and Ross subsequent desired synthesis only begins when students interrogate the 'nooks and crannies' across these themes, developing insights related to previous knowledge, identifying and reflecting on their undergraduate studies.

The content of the table should be considered indicative rather than a rigorous interrogation, one caveat being that the totals include some regional editions of the NG otherwise unavailable to undergraduate students. However, suffice to say that should they be drawn to consulting a recent edition featuring rising sea levels, they will be offered a challenge.

At different times in different places, engineering solutions will no longer suffice. Then the retreat from the coast will begin. In some places there will be no higher ground to retreat to. (Folger, 2013: p. 57)

In addition to Table 3 several titles are shown below to provide the reader with additional evidence of suitable articles for consultation by undergraduate students.

- Phillips (2000) 'Cape Hatteras Lighthouse' (moving the Cape Hatteras lighthouse)

- Long (2002) 'Half life: the lethal legacy of America's nuclear waste' (clean-up at 114 of America's nuclear facilities)

- Molavi (2007) 'Dubai: sudden city - a feverish dream' (urban development and ethics)

- Muller (2008) 'Biomimetics: design by nature' (application of designs from nature to provide solutions for problems in such fields as engineering)

Newman (2009) 'Vanishing Venice' (threats of tourism and flooding in Venice)

Bourne (2010) Part of special issue: Water: our thirsty world (California's world-renowned system of dams, pumps, and canals is now perilously stressed)

- Kunzig (2011) 'Population seven billion' (population, poverty and world's resources)

- Kunzig (2012) 'The city solution' (urban planning, with a focus on city buildings)

- Dobb (2013) 'America's new oil' (hydraulic fracturing (fracking) oil extraction).

It is therefore clear that the subject matter considered by the NG is relevant to civil engineering and in particular undergraduate students who are striving to understand the broad reach of the profession. Regular reading of the NG is not proposed as a panacea for the issues discussed previously, but can form part of a 'blended' learning approach together with other ways of broadening knowledge such as industrial placements, work abroad in developing countries and reading a host of other papers and journals. However, the NG does have some key advantages over other approaches mentioned in that it is widely available, relatively inexpensive and is more accessible academically for those at the start of their career. Moreover, the photographic journalism in this publication is renowned, and as noted by Wilcox (2012) such images have the potential to prompt an emotional response from engineers. Indeed, the NG often focuses on the societal and ethical issues associated with engineering. This can help students develop the necessary character and heart required to meet the needs of future generations.

\section{Conclusion}

Encouraging each undergraduate student to accept that they are the captain of their own 'roving explorer' named curiosity, seeking new knowledge, will help fulfil the call by Fenner et al. (2005: p. 240) for them to be 'self-reflective learners, exposed to a range of different views, and continually encouraged to challenge their own assumptions'. While some undergraduate students are already seeking such knowledge, it is important to the profession, and in fact society as a whole, that there is a wider appreciation of global issues within the undergraduate civil engineering curriculum. This will not only enrich the profession but equip us with the essential tools needed to tackle the challenges of tomorrow.

The analysis of the NG suggests value in regular consultation of this periodical. Other publications that cover global issues examining politics and finance will also guide understanding of a civil engineer's role in society. While travelling across new landscapes as a global engineer, whether physically or cognitively, engineers will meet mentors providing a guiding light to help steer their own curiosity. The article by Grotzinger (2013: p. 38) in the NG - 'Close up on Mars' offers such guidance.

There is no foreign land; it is the traveller only that is foreign. (Robert Louis Stevenson)

\section{REFERENCES}

Arms VM (1994) Personal and professional enrichment: humanities in the engineering curriculum. Journal of Engineering Education, American Society for Engineering 83(2): 141-146.

Armstrong J, Dixon R and Robinson S (1999) The Decision Makers: Ethics for Engineers. Thomas Telford, London, $\mathrm{UK}$

Arup (2012) Engineers and disaster relief, Arup and RedR. See http://www.arup.com/Homepage_Archive/engineers-anddisaster-relief.aspx (accessed 15/08/2013).

ASCE (2013) Hurricane Ike Field Investigations: A Report of Field Operations from October 3-6, 2008. ASCE Press, Virginia, USA.

Banyard J (2004) Water for the world - why is it so difficult? Proceedings of the Institution of Civil Engineers - Civil 
Engineering 159(5): 4-10, http://dx.doi.org/10.1680/cien. 2006.159.5.4.

Baxter JW (1977) Presidential address of John Walter Baxter, President 1976-1977. ICE Proceedings 62(1): 1-13.

Bell S, Chilvers A and Hillier J (2011) The socio-technology of engineering sustainability. Proceedings of the Institution of Civil Engineers - Engineering Sustainability 164(3): 177-184, http://dx.doi.org/10.1680/ensu.900014.

Bingham H (1913) In the wonderland of Peru. National Geographic, 23 April: pp. 387-574.

Birch R (2008) Waste as a driver of change. Part 1: The nature of the problem and why we have it. The Arup Journal 43(1): $15-24$.

Bourn D and Neal I (2008) The Global Engineer: Incorporating Global Skills within the UK Higher Education of Engineers. Engineers against Poverty and Institute of Education. See http://eprints.ioe.ac.uk/839/1/Bourn2008Engineers.pdf (accessed 10/07/2013).

Bourn D and Sharma N (2008) Global and sustainability issues for engineering graduates. Proceedings of the Institution of Civil Engineers - Municipal Engineer 161(3): 199-206, http://dx.doi.org/10.1680/muen.2008.161.3.199.

Bourne JK (2004) Gone with the water. National Geographic 206(4): 88-105.

Bourne JK (2010) Part of special issue: Water: our thirsty world. National Geographic 217(4): 132-149.

Brundtland GH (1987) Report of the World Commission on Environment and Development: Our Common Future. See http://www.un-documents.net/wced-ocf.htm (accessed 05/ 08/2013).

Bryan CDB (1987) The National Geographic Society: 100 Years of Adventure and Discovery. Harry N. Abrams, New York, NY, USA.

Burstall AF (1953) A study of engineering history. Transactions of the Newcomen Society 29(1): 247-254.

B2P (Bridges to Prosperity) (2013) Our History. See http:// bridgestoprosperity.org/who-we-are/our-history/ (accessed 20/08/2013).

Clarke B (2012) The 2011 James Forrest Lecture: Engineering education - a historical perspective of the future. Civil Engineering and Environmental Systems 29(3): 191-212.

Da Silva J (2013) Shifting Agendas: Response to Resilience. The Role of the Engineer in Disaster Risk Reduction. See http:// www.jodasilva.me/Report/Brunel_Report_FINAL $\% 5 B 1 \%$ 5D.pdf (accessed 20/08/2013)

Dobb E (2013) America's new oil, fracking has brought thousands of wells and workers to North Dakota. At what cost? National Geographic 223(3): 28-59.

EWB UK (Engineers Without Borders UK) (2013) Academic Community. See http://www.ewb-uk.org/academiccommunity (accessed 12/08/2103).

Fenner RA, Ainger CM, Cruickshank HJ and Guthrie PM (2005) Embedding sustainable development at Cambridge
University Engineering Department. International Journal of Sustainability in Higher Education 6(3): 229-241.

Fewings P (2009) Ethics for the Built Environment. Taylor and Francis, London, UK.

Folger T (2013) Rising seas. National Geographic 224(3): 30-59. Fox D (1899) Presidential address of Sir Douglas Fox, President 1899-1900. Minutes of the Proceedings 139(1900): 1-24.

Graves W (1993) Water: the power, promise and turmoil of North America's fresh water. National Geographic 184(5A), special edition.

Grigsby DG (2012) Colossal: Engineering the Suez Canal, Statue of Liberty, Eiffel Tower and the Panama Canal. Periscope Publishing, New York, NY, USA.

Grosvenor ES and Morgan W (1997) Alexander Graham Bell: The Life and Times of the Man Who Invented the Telephone. Harry N. Abrams, New York, NY, USA.

Grosvenor G (1957) The National Geographic Society and its Magazine. National Geographic Society, Washington, DC, USA.

Grotzinger J (2013) Close up on Mars, the rover Curiosity is taking portraits of the red planet. National Geographic 224(1): $28-41$.

Gryc $\mathrm{H}$ and Da Silva J (2013) Global engineers thinking locally: creating kindergartens for Africa. Proceedings of the Institution of Civil Engineers - Civil Engineering 166(3): 114-121, http://dx.doi.org/10.1680/cien.12.00042.

Halcrow W (1946) Presidential address of Sir William Thomson Halcrow, President 1946-1947. Journal of the Institution of Civil Engineers 27(1): 1-15.

Harding HJB (1964) Presidential address of Harold John Boyer Harding, President 1963-1964. ICE Proceedings 27(1): $1-16$.

Hartley AC (1960) Presidential address of Arthur Clifford Hartley, CBE, President 1959-1960. ICE Proceedings 15(1): $1-14$.

Hawkshaw JC (1903) Presidential address of John Clarke Hawkshaw, President 1902-1903. Minutes of the Proceedings 151(1): 3-38.

Head P (2008) Entering the Ecological Age - the Engineer's Role. 7th Brunel International Lecture, Institution of Civil Engineers. See http://www.ice.org.uk/Informationresources/Document-Library/Entering-the-ecological-agethe-engineer-s-ro-(1) (accessed 10/06/2013).

Horgan J (2013) The drones come home. National Geographic 223(3): 122-135.

ICE Scotland (2013) Civil Engineers What Do They Do? See http://www.ice.org.uk/getmedia/d4d4d74e-1335-46a1-964e7cd5777802e8/Civil-Engineers-What-do-they-do.aspx (accessed 10/08/2013).

Inglis CE (1941) Presidential address of Prof Charles Edward Inglis, President 1941-1942. Journal of the Institution of Civil Engineers 17(1): 1-18.

Israel FL (1999) Building the Panama Canal (Cultural and 
Engineering Sustainability

Volume 167 Issue ES2
National Geographic:

understand civil engineering

differently

Murray and Ross
Geographical Exploration: Chronicles from National Geographic). Chelsea House, New York, NY, USA. Jackson E (2011) The oceans as a driver of change. The Arup Journal 146(1): 30-41.

Jenkins MC (2012) National Geographic 12 Years, Legendary Photographs, Adventures, and Discoveries that Changed the World. National Geographic Society, Washington, DC, USA.

Johnston CR, Caswell DJ and Armitage GM (2007) Developing environmental awareness in engineers through Engineers Without Borders and sustainable design projects. International Journal of Environmental Studies 64(4): 501-506.

JBM (Joint Board of Moderators) (2009) Degree Guidelines Annex F-Professionalism in Degree Programmes. See http://www. jbm.org.uk/uploads/JBM126_AnnexFProfessionalism.pdf (accessed 10/07/2013).

JBM (2013) Degree Guidelines Annex C - Sustainability in Degree Programmes. See http://www.jbm.org.uk/uploads/ JBM123_AnnexCSustainability.doc2013.pdf (accessed 10/ 07/2013).

Jowitt PW (2006) Engineering Civilisation from the Shadows. 6th Brunel International Lecture. See http://www.ice.org.uk/ Information-resources/Document-Library/BrunelInternational-Lecture-2006-Full-report (accessed 20/08/2013). Jowitt PW (2009) Presidential address of Paul Jowitt, Now is the Time, President 2009-2010. See http://www.ice.org.uk/ getattachment/21ec2403-13ff-43ef-a883-5a23a1f25c27/ Presidential-Address-2009.aspx (accessed 10/08/2013).

Kunzig R (2011) Population seven billion. National Geographic 219(1): 32-69.

Kunzig R (2012) The city solution. National Geographic 220(6) $124-147$.

Litman T (2006) Lessons from Katrina and Rita: what major disasters can teach transportation planners. Journal of Transport Engineering 132(1): 11-18.

Long ME (2002) Half life: the lethal legacy of America's nuclear waste. National Geographic 202(1): 2-33.

Manzoni HJB (1961) Presidential address of Sir Herbert John Baptista Manzoni, President 1960-1961. ICE Proceedings 18(1): $1-14$.

Marchant GJ (2002) Student reading of assigned articles: will this be on the test? Teaching of Psychology 29(1): 49-51.

McCuen RH, Ezzell EZ and Wong MK (2011) Fundamentals of Civil Engineering: An Introduction to the ACE Body of Knowledge. CRC Press, Boca Raton, FL, USA.

McGee WJ (1900) The Lessons of Galveston. National Geographic 11(10): 377-383.

McLean JR (1864) Presidential address of John Robinson McLean, President 1864-1866. Minutes of the Proceedings 23(1864): 151-167.

Millan HL (1996) Poetry in engineering education. Journal of Engineering Education, American Society for Engineering Education 85(2): 157-162.
Miller R and Lessard DR (2000) The Strategic Management of Large Engineering Projects: Shaping Institutions, Risks, and Governance: Shaping Institutions, Risks and Governance. The MIT Press, Cambridge, MA, USA.

Molavi A (2007) Dubai: sudden city - a feverish dream of the future springs from the sands of Dubai. National Geographic 211(1): 94-113.

Morell V (2000) The Blue Nile: Ethiopia's sacred waters. National Geographic 198(6): 2-29.

Morris JG (1983) A century old, the wonderful Brooklyn Bridge. National Geographic 163(5): 564-579.

Muir Wood AM (1978) Presidential address of A.M. Muir Wood, President 1977-1978. Proceedings of the Institution of Civil Engineers - Civil Engineering 64(1): 1-23.

Muir Wood DM (2012) Civil Engineering, A Very Short Introduction. Oxford University Press, Oxford, UK.

Muller T (2008) Biomimetics: design by nature. National Geographic 213(4): 68-91.

Murray M and Dainty A (2009) Corporate Social Responsibility in the Construction Industry. Taylor and Francis, London, UK.

Mustow SE (2006) Procurement of ethical construction products. Proceedings of the Institution of Civil Engineers Engineering Sustainability 159(1): 11-21, http://dx.doi.org/ 10.1680/ensu.2006.159.1.11.

Mustow SN (1993) Presidential address of Stuart Mustow, President 1993-1994, A world to serve. Proceedings of the Institution of Civil Engineers - Civil Engineering 102(1): 2-3, http://dx.doi.org/10.1680/icien.1994.25815.

National Geographic Publications Index (2013) http://shadow. ngs.org/Search/default.aspx?ctx $=5.1033 .0 .0 .3$ (accessed 28/ 08/2013).

Newman C (1994) English Channel Tunnel: the light at the end of the Chunnel. National Geographic 185(5): 36-47.

Newman C (2009) Vanishing Venice. National Geographic, 216(2): 88-113.

Oliver A (2010) Students Celebrate NCE with Festive Posters. See http://www.nce.co.uk/news/business/students-celebrate-ncewith-festive-posters/5212873.article (accessed 05/04/2013).

Pawlyn M (2011) Biomimicry in Architecture. RIBA Publishing, London UK.

Phillips A (2000) Cape Hatteras Lighthouse. National Geographic 197(5): 98-105.

Priemus H, Flyvbjerg B and Van Wee Bert (2008) DecisionMaking on Mega-projects: Cost-Benefit Analysis, Planning and Innovation. Edward Elgar, Cheltenham, UK.

RedR UK (2013) People and Skills for Disaster Relief, Our History. See http://www.redr.org.uk/en/What_we_do/ about-us/history.cfm (accessed 15/08/2013).

Rolt LTC (2007) Thomas Telford. Sutton Publishing, Stroud, UK.

Singleton D (2003) Poverty Alleviation - the Role of the Engineer. 4th Brunel International Lecture. See http://www. ice.org.uk/Pages/Brunel/Series (accessed 20/08/2013). 
Smit T (2011) The Eden Project, Anniversary Edition. New Eden Project Books, Somerset, UK.

Steels HM (2010) A short history for the future of engineering. Proceedings of the Institution of Civil Engineers Management, Procurement and Law 163(4): 185-191, http:// dx.doi.org/10.1680/mpal.2010.163.4.185.

Steels HM (2011) Initial Professional Development for Civil Engineers. ICE Publishing, London, UK.

Stoker R (2012) How Can Middle School Students Learn about Civil Engineering? See http://engineering.mit.edu/live/news/ 2102-how-can-middle-school-students-learn-about-civil (accessed 20/04/2013).

UOS (University of Strathclyde) (2013a) Engineers Without Borders. See http://www.strath.ac.uk/engineering/ undergraduates/ewb/ (accessed 15/08/2013).

uOS (2013b) Civil \& Environmental Engineering. Reading for your Degree. See http://www.strath.ac.uk/civeng/ug/ reading/ (accessed 01/08/13).

UOS (2013c) I'm the ICE Student President of the ICE. See www.strath.ac.uk/civeng/ug/studentpresident (accessed 30/ 08/2013).

UOS (2013d) Encouraged Reading of New Civil Engineering. See www.strath.ac.uk/civeng/ug/readingnce (accessed 30/08/2013).
Venables R (2001) Delivering sustainable development. Proceedings of the 3rd International Brunel Lecture. The Institution of Civil Engineers, London, UK.

Weaver KF, Jeffery D, Gore R, Canby TY and Richards B (1981) Energy, facing up to the problem, getting down to solutions. National Geographic, special report.

Whitby M (2001) ICE presidential address 2001, Visions and Solutions: The Long View. See http://www.mark-whitby. com/MW/2_Article_Vision_and_Solution_files/MW_ICE. illust.pdf (accessed 14/06/2013).

Wilcox K (2012) Bridge Building Group Marks a Milestone, Civil Engineering. See http://www.asce.org/CEMagazine/Article. aspx?id=25769810151 (accessed 07/08/2013).

Wood PK (2003) A road runs through it: Aboriginal citizenship at the edge of urban development. Citizenship Studies 7(4): 463-473.

Wright KR and Zegarra AV (2000) Machu Picchu: A Civil Engineering Marvel. American Society of Civil Engineers Press, Virginia, USA.

Yiatros S, Wadee MA and Hunt GR (2007) The load-bearing duct: biomimicry in structural design. Proceedings of the Institution of Civil Engineers - Engineering Sustainability 160(4): 179-188, http://dx.doi.org/10.1680/ensu.2007.160.4.179.

\section{WHAT DO YOU THINK?}

To discuss this paper, please email up to 500 words to the editor at journals@ice.org.uk. Your contribution will be forwarded to the author(s) for a reply and, if considered appropriate by the editorial panel, will be published as discussion in a future issue of the journal.

Proceedings journals rely entirely on contributions sent in by civil engineering professionals, academics and students. Papers should be 2000-5000 words long (briefing papers should be 1000-2000 words long), with adequate illustrations and references. You can submit your paper online via www.icevirtuallibrary.com/content/journals, where you will also find detailed author guidelines. 